\title{
LAS RELACIONES INTERNACIONALES EN RUSIA: DESARROLLO, ENFOQUES Y DEBATES
}

\author{
Javier MoRAlEs HeRnÁNDEZ*
}

SUMARIO: 1. INTRODUCCIÓN.-2. ORIGEN Y EVOLUCIÓN DESDE EL PERIODO SOVIÉTICO HASTA HOY.-2.1. Las Relaciones Internacionales en la URSS.-2.2. Renovación y apertura al exterior desde 1991.-3. CONCEPCIÓN RUSA DE LAS RELACIONES INTERNACIONALES COMO CIENCIA.-3.1. Relaciones Internacionales versus Política Mundial.-3.2. Posición entre las ciencias sociales.-3.3. Principales enfoques y debates teóricos.-3.3.1. Realismo o nacional-estatismo.-3.3.2. Liberalismo u occidentalismo.-4. ENTRE EL PARTICULARISMO Y LA OCCIDENTALIZACIÓN: LA ESCUELA RUSA DE RELACIONES INTERNACIONALES.-5. CONCLUSIONES.

\section{INTRODUCCIÓN}

1. Desde que, hace cuatro décadas, Stanley Hoffmann definiera las Relaciones Internacionales como "una ciencia social estadounidense» ${ }^{1}$, se ha producido una creciente toma de conciencia del sesgo etnocéntrico que ha marcado su evolución. En palabras de Celestino del Arenal, esta disciplina se ha desarrollado "en un contexto exclusivista, cerrado y provinciano, aunque con pretensiones de validez universal», condicionado tanto "por la ignorancia, cuando no minusvaloración expresa, que esos especialistas [estadounidenses] tienen de otras lenguas y de otros mundos científicos e intelectuales» como por su dependencia de los intereses de política exterior de Estados Unidos $^{2}$. Esto explica que cada vez surjan más voces críticas con ese reduc-

* Profesor Adjunto Doctor de Relaciones Internacionales en la Universidad Europea de Madrid (javier.morales@universidadeuropea.es). Todas las páginas web de referencia han sido consultadas por última vez el 1 de septiembre de 2018. El autor agradece a los profesores Alla Kassianova, Andrei Tsygankov y Natalia Zaslavskaya que le hayan sugerido o facilitado algunas de las fuentes empleadas; aunque asume la responsabilidad de cualquier posible error.

1 HoffmanN, S., «An American Social Science: International Relations», Dcedalus, vol. 106, 1977, núm. 3, pp. 41-60.

2 ARENAL, C. DEL, «Americanocentrismo y Relaciones Internacionales: la seguridad nacional como referente», en Arenal, C. Del y Sanahuja, J. A. (coords.), Teorías de las Relaciones Internacionales, Madrid, Tecnos, 2015, pp. 21-60, esp. p. 44. Véase también AREnAL, C. DEL, Etnocentrismo y teoría de las Relaciones Internacionales: una visión crítica, Madrid, Tecnos, 2014. 
cionismo de la corriente principal o mainstream, que tiende aún a excluir e invisibilizar los trabajos en otros idiomas ${ }^{3}$.

2. En nuestro país, además de reivindicar la contribución de la Escuela Española ${ }^{4}$, algunos autores se han interesado por los debates científicos que tienen lugar en otras culturas; no solamente las del mundo hispanohablante o francófono, sino también aquellas lenguas tradicionalmente menos estudiadas por los internacionalistas españoles, como el chino o el ruso ${ }^{5}$. Sin embargo, como apunta José Antonio Sanahuja, este «giro postoccidental» de las Relaciones Internacionales puede ser interpretado de formas diferentes: desde los enfoques postestructuralistas o postcoloniales, que llegan a negar «la posibilidad misma de cualquier forma de universalismo, por ser necesariamente una manifestación de colonialidad del saber y el poder, y un mecanismo de dominación», hasta quienes tampoco desean caer en un relativismo o multiculturalismo sustentados «en identidades y discursos autorreferenciales, cerrados a la interacción y al diálogo, y de negación de lo universal» ${ }^{6}$. Encontrar un equilibrio entre una concepción global de la ciencia -que no equivale a la mera asimilación de la literatura académica en inglés- y la emergencia de escuelas nacionales diversas, con enfoques propios sobre cada uno de los debates, es uno de los principales retos para el futuro.

3. El presente artículo tiene como objetivo analizar el surgimiento y desarrollo de las Relaciones Internacionales como disciplina científica en Ru-

3 WæVER, O., «The Sociology of a Not So International Discipline: American and European Developments in International Relations», International Organization, vol. 52, 1998, núm. 4, pp. 687-727; Crawford, R. M. A. y JaRVIS, D. S. L. (eds.), International Relations-Still An American Social Science? Toward Diversity in International Thought, Albany, SUNY Press, 2000; Tickner, A. B. y WÆVER, O. (eds.), International Relations Scholarship Around the World, Abingdon, Routledge, 2009; AcHARYA, A. y BUZAN, B. (eds.), Non-Western International Relations Theory: Perspectives On and Beyond Asia, Nueva York, Routledge, 2010; Tickner, A. B. y Blaney, D. L. (eds.), Thinking International Relations Differently, Abingdon, Routledge, 2012.

4 ARENAL, C. DEL, "La aportación de Antonio Truyol y Serra al estudio de las Relaciones Internacionales en España», conferencia en el acto «Homenaje a Antonio Truyol y Serra» celebrado en el Centro de Estudios Políticos y Constitucionales, Madrid, 16 de mayo de 2013, disponible en https://www. academia.edu/4045859/La_aportaci\%C3\%B3n_de_Antonio_Truyol_y_Serra_al_estudio_de_las_Relaciones_Internacionales_en_Espa\%C3\%B1a; CALDUCH CERVERA, R., «La Escuela española de Relaciones Internacionales», en Arenal, C. DEl y Sanahuja, J. A. (coords.), Teorías de las Relaciones Internacionales, Madrid, Tecnos, 2015, pp. 359-376.

5 Trabajos pioneros en España sobre el pensamiento internacional ruso —entonces soviético- fueron los de Mesa, R., "Concepciones marxistas del orden internacional», Sistema, 1977, núm. 19, pp. 4968; CALDUCH, R., «Las relaciones internacionales en la obra de los dirigentes soviéticos: una reflexión teórica», Revista de Estudios Internacionales, vol. 2, 1981, núm. 3, pp. 543-597; ARENAL, C. DEL, «Las Relaciones Internacionales como disciplina científica en la URSS», Sistema, 1983, núm. 52, pp. 65-84. Sobre China, un ejemplo reciente es Pintado Lobato, M., "Hacia una teoría china de las Relaciones Internacionales. Evolución, proyectos teóricos y pertinencia práctica», REDI, vol. 70, 2018, núm. 1, pp. 201-225; así como el Foro sobre «La perspectiva china del Derecho Internacional» en ese mismo número. En cuanto a otros países, pueden mencionarse Bello, I. y PeÑas Esteban, F. J. (coords.), «La Teoría de Relaciones Internacionales en y desde el Sur», número monográfico, Relaciones Internacionales, 2013, núm. 22; ReIG, J., NAVARRo. I. y TABERnERo, C. (coords.), «Resistencias y aportaciones africanas a las Relaciones Internacionales», número monográfico, Relaciones Internacionales, 2014, núm. 26.

6 Sanahuja, J. A., «Reflexividad, emancipación y universalismo: cartografías de la teoría de las Relaciones Internacionales», REDI, vol. 70, 2018, núm. 2, pp. 101-125, esp. pp. 121-123. 
sia, así como sus debates más recientes. Como fuentes principales, se han utilizado obras de autores rusos - artículos en revistas científicas, libros y manuales universitarios- publicadas en su propia lengua o en inglés. La investigación se estructura en cinco partes, incluyendo esta introducción. El segundo apartado describe los comienzos de la disciplina en la Unión de Repúblicas Socialistas Soviéticas (URSS) y los cambios ocurridos tras la disolución de esta. El tercer apartado compara las diversas concepciones rusas acerca del objeto de estudio, su posición dentro de las ciencias sociales y los principales enfoques teóricos. El cuarto apartado profundiza en el debate sobre la conveniencia de mantener una escuela autóctona de Relaciones Internacionales, frente a quienes prefieren asimilar en mayor medida los conceptos y paradigmas anglosajones. Por último, en las conclusiones se reflexiona sobre los obstáculos - de origen interno y externo- que afrontan los internacionalistas rusos para lograr un mayor reconocimiento global.

\section{ORIGEN Y EVOLUCIÓN DESDE EL PERIODO SOVIÉTICO HASTA HOY}

\subsection{Las Relaciones Internacionales en la URSS}

4. Las ciencias sociales se vieron directamente afectadas por el totalitarismo del Estado soviético. El estudio de las Relaciones Internacionales (mezhdunarodnye otnoshenia) se encontraba "situado en un espacio ideológico "sagrado" [...], contenido por estrictas barreras dogmáticas, aislado del pensamiento y los debates internacionales» ${ }^{7}$. Las restricciones a la investigación, la docencia y el debate público se mantuvieron vigentes - aunque con menor intensidad en algunas etapas- hasta la perestroika de Gorbachov ${ }^{8}$.

5. El carácter oficial de la doctrina marxista-leninista hacía que las líneas de investigación quedasen limitadas a la «correlación de fuerzas» entre los bloques de la Guerra Fría, su competición en las distintas regiones geopolíticas, las «contradicciones internas» del capitalismo, el movimiento obrero o las luchas contra el colonialismo. De los tres niveles de análisis - o «imágenes», en la terminología de Kenneth Waltz- tradicionalmente utilizados en la disciplina ${ }^{9}$, el estructural o sistémico era sin duda el predominante, ya que se consideraba que el comportamiento individual de los líderes o los factores

7 Kassianova, A., «IR Studies in Russia: Intellectual Trends and Institutional Developments», conferencia impartida en la European International Relations Summer School «Perspectives on Russian Politics and International Integration», Standing Group on International Relations (SGIR), European Consortium for Political Research (ECPR), Moscú, 2005.

8 Por ejemplo, los libros de autores extranjeros que llegaban a las bibliotecas de las instituciones académicas se guardaban en "secciones de almacenamiento especial» (spetsjrany), con acceso muy restringido. LEBEDEva, M. M., "International Relations Studies in the USSR/Russia: Is There a Russian National School of IR Studies?», Global Society, vol. 18, 2004, núm. 3, pp. 263-278, esp. p. 266.

9 Waltz, K. N., Man, the State, and War: A Theoretical Analysis, Nueva York, Columbia University Press, 1959. 
internos de cada país estaban subordinados a la lógica global de su respectivo sistema económico ${ }^{10}$.

6. La ideología estaba presente también en el método empleado. El objetivo no era explicar la realidad internacional mediante la formulación de hipótesis y su posterior verificación empírica, como defendía el mainstream estadounidense, donde el cientifismo metodológico gozaba de un claro predominio. Por el contrario, en la ciencia soviética se asumía a priori la veracidad de los postulados marxistas-leninistas, los cuales no podían ser sujetos a refutación ${ }^{11}$. Esto daba lugar a que muchas de sus publicaciones consistieran en simples exégesis de discursos y documentos del gobierno, o repeticiones de los dogmas del Partido Comunista de la Unión Soviética (PCUS), carentes del espíritu crítico y emancipador que inspiró las obras del propio Marx ${ }^{12}$.

7. Sin embargo, a partir de la etapa de «deshielo» (ottepel) tras la muerte de Stalin, algunos centros pudieron comenzar a desarrollar trabajos más rigurosos. El verdadero nacimiento de la ciencia soviética de las Relaciones Internacionales se produjo en la década de los sesenta, unificando un campo hasta entonces estudiado de forma parcial por la Historia Diplomática, el Derecho Internacional y la Economía Internacional ${ }^{13}$. El término mezhdunarodnik («internacionalista») se generalizó entonces para referirse a un experto en esta disciplina ${ }^{14}$.

8. La investigación sobre este ámbito se realizaba en los centros de la Academia de Ciencias de la URSS. El principal de ellos era el Instituto de Economía Mundial y Relaciones Internacionales (IMEMO), reabierto por Jruschov en 1956, tras haber sido cerrado por Stalin. Su principal renovación llegaría diez años después, con el nombramiento como director del aperturista Nikolai Inozemtsev, el cual potenciaría especialmente el área de Relaciones Internacionales del instituto, hasta entonces menos desarrollada que la económica ${ }^{15}$. Casi todos los demás centros estudiaban un área geopolítica

10 LYNCH, A., The Soviet Study of International Relations, Cambridge, Cambridge University Press, 1987, pp. 89-107; SERgunin, A., Explaining Russian Foreign Policy Behavior: Theory and Practice, Stuttgart, Ibidem-Verlag, 2016, pp. 68-69.

11 Tsygankov, A. P. y Tsygankov, P. A., «New Directions in Russian International Studies: Pluralization, Westernization, and Isolationism», en Tsygankov, A. P. y Tsygankov, P. A. (eds.), New Directions in Russian International Studies, Stuttgart, Ibidem-Verlag, 2005, pp. 13-35.

12 Sobre las contradicciones entre la «política de poder» de la URSS y su retórica internacionalista y de clase, véase CALDUCH, R., op. cit., nota 5.

13 AREnAL, C. DEL, op. cit., nota 5, pp. 74-77; TiUlin, I. G., «Issledovania mezhdunarodnyj otnosheni v Rossii: vchera, segodnia, zavtra» [La investigación en Relaciones Internacionales en Rusia: ayer, hoy, mañana»], en SHAKLEINA, T. A. (comp.), Vneshniaia politika i bezopasnost sovremennoi Rossii, 19912002, t. III, Moscú, MGIMO/RAMI/INO-Tsentr, 2002, pp. 395-407, esp. pp. 395-397.

14 Zimmerman, W., Soviet Perspectives on International Relations, 1956-1967, Princeton, Princeton University Press, 1969, pp. 43-44.

15 Cherkasov, P. P., IMEMO. Portret na fone epoji [IMEMO: retrato en el contexto de una época], Moscú, Ves Mir, 2004, pp. 257 y ss.; Zimmerman, W., op. cit., nota 14, p. 73. La disputa entre Stalin y el economista de origen húngaro Yevgeni Varga, primer director de IMEMO —entonces llamado Instituto de Economía Mundial y Política Mundial (IMJiMP)—, que acabaría llevando al cierre del centro en 1948, se narra también en LYNCH, A., op. cit., nota 10, pp. 20-25. 
concreta: Instituto de Estados Unidos y Canadá, Instituto de Estudios Orientales, Instituto de Latinoamérica, Instituto de África, Instituto del Lejano Oriente, Instituto de Economía del Sistema Socialista Mundial e Instituto del Movimiento Obrero Internacional. Frente a las universidades, la Academia de Ciencias tenía la ventaja de poder editar sus propias publicaciones y mantener algunos contactos con instituciones extranjeras ${ }^{16}$.

9. La enseñanza de esta disciplina estaba limitada entonces a la formación universitaria de los futuros diplomáticos, así como otros profesionales que fueran a desarrollar su trabajo en el extranjero. La primera Facultad de Relaciones Internacionales comenzó a funcionar en 1943 en la Universidad Estatal de Moscú; un año después, se transformó en un centro adscrito al Ministerio de Asuntos Exteriores, con el nombre de Instituto Estatal de Relaciones Internacionales de Moscú (MGIMO). En los años siguientes, MGIMO fue dividiéndose a su vez en distintas facultades: Relaciones Internacionales, Economía Internacional, Derecho Internacional y Periodismo Internacional ${ }^{17}$.

10. Al principio, el plan de estudios de la Facultad de Relaciones Internacionales incluía sobre todo asignaturas de Historia - muchos de los profesores eran historiadores o diplomáticos-, algunas clases de Economía y Derecho, y un mínimo de dos idiomas extranjeros. Desde la década de los setenta, se fueron añadiendo nuevas materias con un enfoque más politológico y aplicado al análisis práctico de la actualidad internacional ${ }^{18}$. Todo ello hacía que sus graduados fueran muy valorados por las autoridades, aunque a la vez se mantenía el control ideológico sobre la docencia ${ }^{19}$. MGIMO tuvo el monopolio de esta carrera durante casi todo el periodo soviético, salvo los años 1944-1955, en los que existió otra Facultad de Relaciones Internaciona-

16 Tiulin, I. G., «Novye tendentsii v rossiiskij issledovaniaj mezhdunarodnyj otnosheni» [«Nuevas tendencias en la investigación rusa sobre Relaciones Internacionales»], en ToRKUNOV, A. V. (ed.), Sovremennye mezhdunarodnye otnoshenia i mirovaia politika. Uchebnik, Moscú, MGIMO, 2004, p. 37; Lebedeva, M. M., op. cit., nota 8, p. 264. Tras el fin de la URSS, el Instituto de Economía del Sistema Socialista Mundial se fusionó con el Instituto de Economía; mientras que el Instituto del Movimiento Obrero Internacional se transformó en Instituto de Política Comparada, después absorbido por el Instituto de Sociología.

17 «Istoria MGIMO» [ «Historia de MGIMO»], disponible en https://mgimo.ru/about/history/; «Istoria fakulteta» [ Historia de la Facultad»], disponible en https://mgimo.ru/study/faculty/mo/docs/istoriyafakulteta/. MGIMO impartía carreras universitarias, mientras que la Escuela Diplomática Superior —después, Academia Diplomática- del Ministerio de Asuntos Exteriores se ocupaba de la formación y actualización de los diplomáticos en activo. Ambas instituciones ofrecían programas de doctorado. Lebedeva, M. M., «Obrazovanie v oblasti mezhdunarodnyj otnosheni v Rossii» [«La enseñanza de las Relaciones Internacionales en Rusia»], Vestnik Sankt-Peterburgskogo universiteta (Politologia. Mezhdunarodnye otnoshenia), 2016, núm. 4, pp. 66-77, esp. p. 68.

18 Chechevishnikov, A. L., "40 let IMI: ot problemnoi laboratorii k Institutu mezhdunarodnyj issledovani» [ «40 años del IMI: del Laboratorio de Problemas al Instituto de Estudios Internacionales»], Vestnik MGIMO-Universiteta, 2016, núm. 2 (47), pp. 234-241; "Nauchnye shkoly» [Escuelas científicas»], pp. 3-9, disponible en https://mgimo.ru/upload/2016/07/mgimo-scientific-schools.pdf; LEBEDEVA, M. M., op. cit., nota 17, p. 68.

19 Kulagin, V. M., «Ucheba v MGIMO 50 let nazad» ["Estudiar en MGIMO hace 50 años»], 14 de octubre de 2014, disponible en https://mgimo.ru/about/news/experts/260543/. 
les en la Universidad Estatal de Kiev. En el resto de la URSS, algunas universidades impartían disciplinas como los Estudios Orientales (vostokovedenie), pero sin un enfoque propiamente internacionalista ${ }^{20}$.

11. Durante el mandato de Jruschov, se permitió acceder con menos restricciones a las obras de autores extranjeros como Hans Morgenthau, Morton Kaplan, Raymond Aron o Thomas Schelling. Esto impulsaría una evolución intelectual de los académicos soviéticos hacia el realismo predominante en Occidente, aunque aún se vieran obligados a revestirlo de un lenguaje marxista. Así, en 1969 se creó en IMEMO un departamento para el estudio de cuestiones teóricas, que llegó a publicar un volumen - realmente, una antología encubierta del pensamiento occidental- sobre los enfoques «burgueses» utilizados en Estados Unidos, Reino Unido, Francia, Alemania Federal e Italia ${ }^{21}$. La primera asignatura de Teoría de las Relaciones Internacionales comenzó a impartirse en MGIMO en $1973^{22}$. Sin embargo, el interés por los debates en los países capitalistas hizo que este campo de estudio adquiriese cierta reputación de deslealtad ideológica ${ }^{23}$.

12. El caldo de cultivo para un progresivo cambio de mentalidad se formó además en la revista Problemy mira i sotsializma (Problemas de la Paz y el Socialismo), donde trabajaron como redactores algunos de los que después serían los principales expertos soviéticos en Relaciones Internacionales, como Georgi Arbatov, Anatoli Cherniayev, Vladimir Lukin o el propio Nikolai Inozemtsev. La publicación tenía su sede en Praga, lo que permitió a esos jóvenes vivir en un país socialista más abierto, cuyo proceso de reformas les suscitaba gran interés. Estas esperanzas se verían truncadas por el aplastamiento de la "primavera de Praga», acogido por ellos con un sentimiento de vergüenza, que contribuiría - años después- a su compromiso con la perestroika ${ }^{24}$.

20 Sergunin, A., op. cit., nota 10, pp. 71-72; Lebedeva, M. M., op. cit., nota 8, pp. 267-268; «International Relations and Foreign Policy Chair», disponible en http://www.iir.edu.ua/en/education/international_relations/mvzp/.

21 Gantman, V. I. (ed.), Sovremennye burzhuaznye teorii mezhdunarodnyj otnosheni. Kriticheski analiz [Teorías burguesas contemporáneas de las Relaciones Internacionales: un análisis crítico], Moscú, Nauka, 1976. Los contactos de IMEMO con académicos estadounidenses y británicos se mencionan en LEBEDEVA, M. M., op. cit., nota 8, p. 266.

22 JRustaliov, M., «Dve vetvi TMO v Rossii» [ «Las dos ramas de la Teoría de Relaciones Internacionales en Rusia»], Mezhdunarodnye protsessy, vol. 4, 2006, núm. 2 (11), pp. 119-128.

23 Shakleyina, T. A. y Bogaturov, A. D., «The Russian Realist School of International Relations», en Tsygankov, A. P. y Tsygankov, P. A., op. cit., nota 11, pp. 61-81. Marina Lebedeva narra una reveladora anécdota ocurrida en MGIMO en 1967. En la lectura de una tesis sobre el pensamiento realista estadounidense, algunos miembros del tribunal demostraron no conocer el nombre de Hans Morgenthau, creyendo que las citas a este autor se referían al antiguo secretario del Tesoro, Henry Morgenthau. Tras la defensa, el Ministerio de Educación Superior — que tenía la última palabra en la calificación- llegó a acusar al doctorando de "revisionismo»; aunque al final acabaría por concederle el título. Lebedeva, M. M., «Predmetnoie pole i predmetnye polia mirovoi politiki» [«El objeto de estudio y los objetos de estudio de la Política Mundial»], Mezhdunarodnye protsessy, vol. 2, 2004, núm. 2 (5), pp. 97-108, esp. p. 107.

24 English, R. D., Russia and the Idea of the West: Gorbachev, Intellectuals, and the End of the Cold War, Nueva York, Columbia University Press, 2000, pp. 70-71, 111. 
13. El «estancamiento» (zastoi) de la etapa de Brezhnev tuvo consecuencias contradictorias para las ciencias sociales. Por una parte, el Comité Central lanzó una campaña represiva contra los académicos considerados «revisionistas»: una muestra fue el despido, en 1972, del director y unos 140 trabajadores del Instituto de Investigación Social Concreta - hoy, Instituto de Sociología - de la Academia de Ciencias. Al mismo tiempo, el clima de distensión en la Guerra Fría permitió un incremento sustancial de los viajes de intercambio, participación en congresos internacionales y acceso a la literatura científica publicada en el extranjero ${ }^{25}$.

14. Pero fue el ascenso de Gorbachov al Kremlin lo que hizo posible que estos intelectuales no solo dejasen de ser perseguidos, sino que se convirtieran en inspiradores del «nuevo pensamiento» (novoie myshlenie) en política exterior. Por ejemplo, todavía con Andropov en el poder, Gorbachov maniobró para que se permitiera a Alexander Yakovlev volver de su «exilio» de una década como embajador en Canadá, donde había sido enviado como castigo por publicar un artículo crítico. A su regreso en 1983, Yakovlev ocupó el puesto de director de IMEMO - vacante tras la muerte de Inozemtsev un año antes-, desde el que comenzaría a promover estudios que abogaban abiertamente por reformas profundas y cooperación con Occidente ${ }^{26}$.

15. De esta forma, la lógica de la confrontación entre clases y sistemas económicos se vio desplazada en los últimos años de la URSS por una mayor preocupación por problemas globales como la «carrera de armamentos» y el riesgo de guerra nuclear, que ponían en peligro la supervivencia de toda la humanidad ${ }^{27}$. La visión gorbachoviana de una "casa común europea», en la que todos los países - tanto capitalistas como socialistas- debían ponerse de acuerdo para establecer reglas de convivencia, se reflejó en la creación en 1987 del Instituto de Europa de la Academia de Ciencias. Dentro de esta, se formó al año siguiente un Ârea de Relaciones Internacionales para coordinar a todos sus centros sobre estas cuestiones, que hasta entonces estaban adscritos al Área de Economía ${ }^{28}$.

\subsection{Renovación y apertura al exterior desde 1991}

16. Las Relaciones Internacionales de la Federación Rusa independiente se abrieron poco a poco al pluralismo teórico y metodológico. Los autores extranjeros fueron cada vez más leídos y citados; no solo los estadounidenses, sino también británicos y franceses, de los que ya se habían traducido algunas obras

25 Ibid., pp. 125-126, 134.

26 Ibid., pp. 184-185.

27 Sodupe, K. y Moure, L., «Conceptos soviéticos fundamentales de las Relaciones Internacionales», en Sodupe, K. y Moure, L. (eds.), Rusia en la era postsoviética, Bilbao, Universidad del País Vasco, 2011, pp. 61-103, esp. pp. 95-96.

28 Simonia, N. A. y Semionov, A. I., "Obiekt issledovania - mirovaia politika i ekonomika» [«Objeto de estudio: la política y economía mundiales»], en SHAKLEINA, T. A., op. cit., nota 13, p. 386. 
en el periodo anterior ${ }^{29}$. Sin embargo, la transición económica de la década de los noventa tuvo un serio impacto tanto en la investigación como en la enseñanza. Los institutos de la Academia de Ciencias, completamente dependientes de la financiación estatal, tuvieron que recortar drásticamente sus actividades; muchos científicos buscaron trabajo en otros sectores o en el extranjero. Las ayudas del programa TEMPUS TACIS de la Unión Europea y de fundaciones privadas estadounidenses o alemanas fueron decisivas durante esos años ${ }^{30}$.

17. En 1994 se produjo una reforma de esta carrera para orientarla a nuevos perfiles profesionales, como las finanzas, la información o la comunicación intercultural, ya no solo la diplomacia ${ }^{31}$. El resultado ha sido una expansión por todo el país del Grado en Relaciones Internacionales, impartido hoy en 77 universidades, desde San Petersburgo a Vladivostok ${ }^{32}$. Solamente en la capital, al tradicional predominio de MGIMO — aún la más prestigiosa- se han sumado la Universidad Estatal Lomonosov de Moscú ${ }^{33}$, la Escuela Superior de Economía, la Universidad Rusa de la Amistad de los Pueblos o la Universidad Estatal Rusa de Humanidades, entre otras ${ }^{34}$.

18. La consolidación de una comunidad científica de ámbito nacional debe mucho al profesor Alexei Bogaturov, que ha ejercido una labor de verdadero mentor en el marco del Foro Científico-Educativo de Relaciones Internacionales (NOFMO), entidad sin ánimo de lucro fundada por él. Entre sus principales iniciativas ha estado un curso intensivo para jóvenes académicos, el «Instituto Metodológico de Relaciones Internacionales», impartido en veintiséis ediciones entre 1995 y 2012. Los participantes —becados por la organización, y procedentes en su mayoría de universidades de las regionestenían así la oportunidad de conocer a profesores de Moscú, presentarles sus trabajos y establecer redes de colaboración ${ }^{35}$.

19. Con respecto a la libertad académica, aunque ya no hay una represión equiparable a la del periodo comunista, existen ciertos incentivos para

29 Lebedeva, M. M., op. cit., nota 8, p. 276.

30 Tiulin, I. G., op. cit., nota 16, p. 37.

31 «Federalny gossudarstvenny obrazovatelny standart vysshego obrazovania - bakalavriat po napravleniu podgotovki 41.03.05 Mezhdunarodnye otnoshenia» [«Normativa estatal federal de educación superior - Grado en la especialidad 41.03.05 Relaciones Internacionales»], 15 de julio de 2017, disponible en $h t t p: / / w w w . e d u . r u / f i l e / d o c s / 2017 / 06 / m 555 . p d f \# p a g e=3$; SERGUNIN, A., op. cit., nota 10 , p. 72.

32 Rusia, como miembro del Espacio Europeo de Educación Superior (EEES) desde 2003, ha adoptado un sistema de grado (bakalavriat) de cuatro años y máster (magistratura) de dos; en lugar de las antiguas titulaciones de especialista (spetsialist), de cinco años. "Mezhdunarodnye otnoshenia (bakalavr)»[«Relaciones Internacionales (Grado)»], disponible en http://www.edu.ru/abitur/act.7/ fgos.031900/st.1/index.php; LeBEDEVA, M. M., op. cit., nota 17, p. 71.

33 Esta universidad, la mayor y más antigua del país, inauguró una Facultad de Política Mundial en 2003 y una Facultad de Procesos Globales en 2005. Además, hay un Departamento de Relaciones Internacionales y Procesos de Integración en la Facultad de Ciencia Política; un Departamento de Sociología de las Relaciones Internacionales en la Facultad de Sociología; y un Departamento de Organizaciones Internacionales y Problemas de la Gobernanza Global en la Facultad de Gestión Pública.

34 Tiulin, I. G., op. cit., nota 16, p. 37; Lebedeva, M. M., op. cit., nota 8, p. 272; Sergunin, A., op. cit., nota 10, pp. 74-77.

${ }_{35}$ Zimne-letni metodologicheski institut mezhdunarodnyj otnosheni [Instituto Metodológico de Verano e Invierno de Relaciones Internacionales] disponible en http://www.obraforum.ru/imo.htm. 
mantenerse dentro de posiciones ideológicas mayoritarias: bien sea para no «significarse» ante los superiores, o para conseguir fondos públicos para la investigación. En un régimen no democrático, trabajar en instituciones dependientes del Estado implica también adoptar, al menos, cierto grado de autocensura, cuando no recibir presiones externas. Por ejemplo, es habitual que los investigadores rusos empleen un tono más cauto para analizar la política exterior de su país que para referirse a las potencias occidentales ${ }^{36}$. Todo ello hace necesario realizar una lectura cuidadosa para detectar posibles sesgos u omisiones, pero - como es lógico- tampoco invalida de entrada cualquier trabajo realizado por estos autores, la mayoría de los cuales tienen amplios conocimientos sobre el área geográfica de su especialidad.

20. Finalmente, hay que mencionar la creación en 1999 de la Asociación Rusa de Estudios Internacionales como uno de los hitos en el desarrollo de la disciplina en ese país. Su actividad más destacada es un congreso anual o bienal: el celebrado en septiembre de 2017 estuvo dividido en 56 paneles y cuatro mesas redondas, con un total de más de mil asistentes inscritos ${ }^{37}$.

\section{CONCEPCIÓN RUSA DE LAS RELACIONES INTERNACIONALES COMO CIENCIA}

\subsection{Relaciones Internacionales versus Política Mundial}

21. En la actualidad, las perspectivas rusas sobre el objeto de las Relaciones Internacionales pueden agruparse en dos tendencias: una más tradicional, identificada con el estudio de las relaciones entre Estados, y otra que prefiere centrarse en los actores no estatales y procesos transnacionales. La primera podría encuadrarse en el neorrealismo o realismo estructural, aunque con ciertas peculiaridades respecto a la teoría original de Kenneth Waltz, como un mayor énfasis en la especificidad cultural de cada país ${ }^{38}$. Sus seguidores investigan el desarrollo histórico y los cambios en la estructura de poder del sistema internacional, o de regiones geopolíticas concretas, combinando la teoría con el análisis de la situación presente y su posible evolución.

${ }^{36}$ Los límites a las críticas hacia la política exterior parecen especialmente claros en el caso de MGIMO, que depende del Ministerio de Asuntos Exteriores. Por ejemplo, uno de sus profesores fue despedido tras escribir un artículo muy duro contra la anexión de Crimea, en el que llegaba a compararla con el Anschluss de la Alemania nazi sobre Austria. Zubov, A., «Eto uzhe bylo» [Esto ya ha pasado»], Vedomosti, 1 de marzo de 2014, disponible en https://www.vedomosti.ru/opinion/articles/2014/03/01/ andrej-zubov-eto-uzhe-bylo; "Professor Says Sacked Over Opinion Article Against Possible Ukraine Invasion", The Moscow Times, 5 de marzo de 2014, disponible en https://themoscowtimes.com/articles/ professor-says-sacked-over-opinion-article-against-possible-ukraine-invasion-32689.

37 Rossiiskaia assotsiatsia mezhdunarodnyj issledovani (RAMI) / Russian International Studies Association (RISA), disponible en http://www.risa.ru.

38 ZaslavsKaya, N., "Teaching IR Theory at Russian Universities: The Russian Version vs the Western Version", comunicación presentada en la 59th Annual Convention of the International Studies Association (ISA), San Francisco, 2018, p. 7. 
22. La segunda perspectiva es defendida por Marina Lebedeva y otros representantes del paradigma liberal en el mundo académico ruso. Esta autora utiliza el nombre de mirovaia politika (Política Mundial) para referirse a la concepción más amplia de la disciplina que se denomina World Politics en inglés, surgida en la década de los setenta como alternativa al paradigma realista predominante, por impulso de las teorías de la «interdependencia compleja» de Robert Keohane y Joseph $\mathrm{Nye}^{39}$. A diferencia de las Relaciones Internacionales clásicas, esta versión rusa de la Política Mundial se centra en las relaciones transnacionales entre actores no estatales, la Economía Política Internacional e incluso cuestiones propias de la Ciencia Política, como la Política Comparada ${ }^{40}$.

23. Esta diferencia puede observarse en la propia estructura de las universidades. En MGIMO, un ejemplo de la primera visión sería el Departamento de Análisis Aplicado de los Problemas Internacionales de la Facultad de Relaciones Internacionales - dirigido inicialmente por Alexei Bogaturov, y actualmente por Tatiana Shakleina-, continuador de la «escuela de análisis sistémico-estructural» de la época soviética ${ }^{41}$. La segunda estaría presente en el Departamento de Procesos Políticos Mundiales de la Facultad de Ciencia Política, cuya directora es la propia Marina Lebedeva ${ }^{42}$. Algo similar ocurre en la Universidad Estatal de Moscú: la Facultad de Política Mundial está - pese a su nombre- muy enfocada en los Estudios Estratégicos, por influencia de su decano y reconocido experto en esos temas, Andrei Kokoshin. En cambio, la Facultad de Procesos Globales se ocupa más de lo que en ruso se denomina globalistika, que correspondería a los Global Studies en inglés ${ }^{43}$.

24. Hoy parece haberse alcanzado ya cierto consenso en torno a la importancia de los fenómenos transnacionales, aunque sin olvidar el papel de los Estados. Así, Bogaturov considera que las dos perspectivas comparten algunas de sus áreas de investigación, como la Teoría de las Relaciones Internacionales, mientras que otras se encuentran más claramente dentro de una de ellas ${ }^{44}$. La definición más inclusiva es la de Pavel Tsygankov,

39 Lebedeva se inspira en obras como el monográfico — después publicado en forma de librocoordinado por Nye, J. S. y Keohane, R. O., "Transnational Relations and World Politics», International Organization, vol. 25, 1971, núm. 3.

40 Lebedeva, M. M., Mirovaia politika. Uchebnik [Manual de Política Mundial], Moscú, 4. ${ }^{\text {a }}$ ed., KnoRus, 2018, pp. 68-71; LebedevA, M. M. y Melville, Y. A., "Sravnitelnaia politologia, mirovaia politika, mezhdunarodnye otnoshenia: razvitie predmetnyj oblastei» [«Política Comparada, Política Mundial, Relaciones Internacionales: desarrollo de áreas temáticas»], en SHAKLEINA, T. A., op. cit., nota 13, p. 408; LEBEDEVA, M. M., op. cit., nota 23.

41 «Kafedra prikladnogo analiza mezhdunarodnyj problem (PAMP)» [ [Departamento de Análisis Aplicado de los Problemas Internacionales»], disponible en https://mgimo.ru/study/faculty/mo/kpamp/; «Nauchnye shkoly», op. cit., nota 17, pp. 8-9.

42 «Kafedra mirovyj politicheskij protsessov» [Departamento de Procesos Políticos Mundiales»], disponible en https://mgimo.ru/study/faculty/sgp/kmpp/; LeBEDEVA, M. M., op. cit., nota 17, p. 72.

43 «Fakultet mirovoi politiki» [«Facultad de Política Mundial»], disponible en http://fmp.msu.ru/; «Fakultet globalnyj protsessov» [«Facultad de Procesos Globales»], en http://fgp.msu.ru/.

44 Bogaturov, A. D., «Poniatie mirovoi politiki v teoreticheskom diskurse» [El concepto de Política Mundial en el discurso teórico»], en Mezhdunarodnye protsessy, vol. 2, 2004, núm. 1 (4), pp. 16-33, esp. p. 31. 
quien opta por el nombre de «Relaciones Internacionales y Política Mundial» (mezhdunarodnye otnoshenia $i$ mirovaia politika) para reflejar la necesidad de investigar ambas cuestiones, rechazando que deba sustituirse una por otra:

«Muchos autores creyeron al principio que el fenómeno de la política mundial había "abolido" las relaciones internacionales tradicionales. Hoy ya está claro que, en realidad, todo es mucho más complicado. Los nuevos fenómenos no eliminan por completo los ya existentes; los cambian solo parcialmente, y parecen estar construidos sobre ellos» ${ }^{45}$.

25. En cualquier caso, todos ellos reconocen que se trata de una discusión más habitual en la literatura académica rusa que en los países anglosajones, donde parece en gran medida superada: los términos International Relations y World Politics se utilizan hoy con frecuencia como sinónimos, si bien para algunos autores el segundo sigue teniendo un significado más inclusivo y menos estatocéntrico ${ }^{46}$. No obstante, en el conjunto de la disciplina ya se ha asumido con normalidad el estudio de los actores no estatales y los cambios derivados de la globalización; a lo que ha contribuido tanto el paradigma liberal como — desde una visión más sociológica- el constructivismo social y los enfoques reflectivistas.

26. Por otra parte, aunque en Rusia las Relaciones Internacionales siguen priorizando el estudio de los fenómenos políticos, económicos y de seguridad, en sus publicaciones más recientes se observa una creciente atención a otros aspectos de las relaciones sociales y humanas, como el impacto de la cultura, la educación o los cambios tecnológicos. Esto hace que se aproximen gradualmente al concepto amplio de Relaciones Internacionales -no limitado solo a la Política Internacional- que se emplea en otros países, incluyendo la doctrina española ${ }^{47}$.

\subsection{Posición entre las ciencias sociales}

27. Para comprender el lugar que ocupan las Relaciones Internacionales en el panorama científico ruso, podemos comenzar por su clasificación de acuerdo con la Comisión Superior de Acreditación (VAK). Este organismo oficial establece el catálogo de posibles especialidades de los programas de doctorado; cada una de las cuales se adscribe a una rama más amplia de

45 Tsygankov, P. A. (ed.), Mezhdunarodnye otnoshenia i mirovaia politika. Uchebnik dlia bakalavriata i magistratury [Relaciones Internacionales y Politica Mundial. Manual para estudios de grado y máster], Moscú, Yurait, 2018, pp. 14-15.

46 Sobre esta distinción, véase AREnAL, C. DEL, Introducción a las Relaciones Internacionales, 3. a ed., Madrid, Tecnos, 1990, p. 23. Por ejemplo, en uno de los manuales universitarios más utilizados en inglés, se afirma que World Politics es el estudio de las relaciones políticas entre los diferentes tipos de actores presentes en el mundo, mientras que las International Relations o International Politics están centradas sobre todo en los Estados. BaYLIS, J., SMith. S. y OwEns, P. (eds.), The Globalization of World Politics: An Introduction to International Relations, 7. ${ }^{a}$ ed., Oxford, Oxford University Press, 2017, p. 2.

47 ARENAL, C. DEL, op. cit., nota 46, p. 22. 
las ciencias, que es la que figura en el título de doctor. La especialidad más identificada con Relaciones Internacionales es «Problemas Políticos de las Relaciones Internacionales y del Desarrollo Global y Regional», englobada en la rama de las Ciencias Políticas, en plural ${ }^{48}$. Así, los internacionalistas que realizan una tesis obtienen el mismo título de «Doctor en Ciencias Políticas» (kandidat politicheskij nauk) - aunque por una especialidad diferente- que quienes han investigado sobre temas de Ciencia Política en sentido estricto.

28. Esta común naturaleza politológica no implica, sin embargo, que las Relaciones Internacionales sean tratadas como una subdisciplina de la Ciencia Política, como ocurre en el sistema estadounidense. Por el contrario, en la literatura académica rusa se las define como una disciplina en sí misma: una «ciencia internacional-política» (mezhdunarodno-politicheskaia nauka) diferenciada de la Ciencia Política (politicheskaia nauka o politologia) ${ }^{49}$. Esta identidad propia se refleja en la existencia de departamentos —e incluso facultades-de Relaciones Internacionales dentro de las universidades, a lo que contribuye su larga trayectoria como titulación oficial. No obstante, pueden encontrarse también áreas interdisciplinares como los Estudios Regionales Extranjeros (zarubezhnoie regionovedenie, equivalentes a los Area Studies en inglés) ${ }^{50}$, en los que confluyen especialistas en un mismo país o área geográfica.

29. La autonomía científica de las Relaciones Internacionales, similar a la de otros países europeos, se debe a su evolución histórica: mientras que estas ya contaban con instituciones propias desde los años cuarenta y cincuenta, la Ciencia Política solo logró ser reconocida a finales de los ochenta, puesto que su lugar estaba ocupado por la llamada «Ciencia del Estado y el Derecho" - de carácter fundamentalmente jurídico-y los cursos de teoría marxista-leninista ${ }^{51}$. Pese a que algunos de los proyectos para introducir la Ciencia Política en la URSS llegaron a proponer que absorbiera las Relaciones Internacionales ${ }^{52}$, eso no llegó a realizarse; el tardío desarrollo y compa-

48 «Pasporta nauchnyj spetsialnostei» [Descriptores de especialidades científicas»], disponible en http://vak.ed.gov.ru/316.

49 Tsygankov, P. A., op. cit., nota 45, cap. 1; Tsygankov, A. P. y Tsygankov, P. A. (eds.), Rossiiskaia nauka mezhdunarodnyj otnosheni: novyie napravlenia [La ciencia rusa de las Relaciones Internacionales: nuevos enfoques], Moscú, Per Se, 2005; Barnashov, O. V., "Mezhdunarodno-politicheskaia nauka v RF» [ ¿La ciencia internacional-política en la Federación Rusa»], Vestnik RUDN (Mezhdunarodnye otnoshenia), vol. 15, 2015, núm. 3, pp. 185-197.

50 Los Estudios Regionales también existen en Rusia como titulación universitaria. Por ejemplo, dentro de la Universidad Estatal de Moscú se imparte en la Facultad de Lenguas Extranjeras y Estudios Regionales - para las especialidades de Europa, Eurasia y América del Norte- y en el Instituto de Países de Asia y África.

51 El primer Departamento de Ciencia Política fue el de la Facultad de Filosofía de la Universidad Estatal de Leningrado, en 1988. También en esa institución —ya con el nombre de Universidad Estatal de San Petersburgo- se abrió la primera Facultad de Relaciones Internacionales fuera de Moscú, en 1994. Lebedeva, M. M., op. cit., nota 8, pp. 272-274; LebedeVA, M. M., op. cit., nota 17, p. 70.

52 Theen, R. H. W., "Political Science in the USSR: “To Be, Or Not To Be". Some Reflections on the Implications of a Recent Soviet Critique of American Political Science», World Politics, vol. 23, 1971, núm. 4, pp. 684-703; ArENAL, C. DEL, op. cit., nota 5, pp. 70-72. 
rativa debilidad institucional de la primera hizo que ambas permanecieran como áreas diferenciadas. Como señala Marina Lebedeva,

«en Rusia - pero no solo en Rusia- las Relaciones Internacionales y la Ciencia Política se desarrollaron principalmente de forma separada, aunque paralela. [...] la Ciencia Política fue ignorada en gran medida por los internacionalistas, considerando la política interna solo en la medida en que influyera en la política exterior. El resultado final fue que internacionalistas y politólogos tuvieron "sus" respectivas literaturas científicas, asociaciones profesionales, revistas científicas, etc. $)^{53}$.

30. Las Relaciones Internacionales rusas estudian, por tanto, «la interacción, el intercambio de actividades y de sus resultados, que tiene lugar entre diferentes actores sociales - principalmente, los Estados- en alguno de los ámbitos de la vida pública, y que supera las fronteras»; una definición ya no limitada exclusivamente a los actores estatales, pero todavía muy enfocada en ellos ${ }^{54}$. Con respecto a la metodología, los internacionalistas se distinguen por emplear un repertorio multidisciplinar de técnicas de investigación: politológicas, historiográficas, jurídicas, sociológicas o económicas. La tradicional importancia del método histórico se refleja en varias universidades de las regiones rusas, donde la carrera de Relaciones Internacionales se ha creado dentro de la Facultad de Historia ${ }^{55}$.

31. Según Pavel Tsygankov, el núcleo de la disciplina estaría constituido por la Teoría de las Relaciones Internacionales, como principal elemento diferenciador respecto de otras ciencias. En cuanto a sus subdisciplinas, podrían identificarse entre otras los Estudios de Seguridad, la Economía Política Internacional, las Organizaciones Internacionales o el Análisis de Política Exterior, si bien todas ellas tienen sus raíces en la teoría ${ }^{56}$. No obstante, los seguidores del enfoque liberal destacan la creciente interpenetración de la política interior y exterior; lo que lleva a Marina Lebedeva a considerar que debería establecerse un diálogo más estrecho con la Ciencia Política, aunque enfatizando que las Relaciones Internacionales «no pueden ni deben convertirse en una parte» de aquella ${ }^{57}$.

53 Lebedeva, M. M., op. cit., nota 8, pp. 273-274. Véase también Lebedeva, M. M., «Rossiskie mezhdunarodnye issledovania: vozmozhny vklad v razvitie obschemirovoi nauki» [Los estudios internacionales rusos: posible contribución al desarrollo de la ciencia mundial»], en Vestnik SanktPeterburgskogo universiteta (Politologia. Mezhdunarodnye otnoshenia), 2015, núm. 2, pp. 83-95, esp. p. 91; Lebedeva, M. M., «Rossiiskie issledovania i obrazovanie v oblasti mezhdunarodnyj otnosheni: 20 let spustia» «La investigación y enseñanza rusas en el ámbito de las Relaciones Internacionales, veinte años después»], Documento de Trabajo del Consejo Ruso de Asuntos Internacionales, núm. 2/2013, p. 8, disponible en http://russiancouncil.ru/activity/workingpapers/rossiyskie-issledovaniya-i-obrazovanie-v-oblasti-mezhdunarod/.

54 Tsygankov, P. A., "Mezhdunarodnye otnoshenia i mirovaia politika": konsolidatsia uchebnonauchnoi distsipliny?» [«"Relaciones Internacionales y Política Mundial”: ¿consolidación de una disciplina académico-científica?»], en Mezhdunarodnye protsessy, vol. 11, 2013, núms. 3-4 (34-35), pp. 6-20, esp. p. 12.

55 Lebedeva, M. M. y Melville, Y. A., op. cit., nota 40, pp. 413-414.

56 Tsygankov, P. A., op. cit., nota 45, pp. 27-28.

57 Lebedeva, M. M., «Rossiskie mezhdunarodnye issledovania...», op. cit., nota 53, p. 93; LEBEDEVA, M. M., op. cit., nota 40, p. 70. 


\subsection{Principales enfoques y debates teóricos}

32. Como hemos visto, las Relaciones Internacionales soviéticas prestaron una escasa atención al desarrollo de teorías, dado que el marxismoleninismo era el único enfoque permitido. Solo a partir de los años sesenta, el mayor acceso a la literatura científica extranjera sirvió para introducir el paradigma realista, que ya estaba presente de facto en la estrategia de la URSS durante la Guerra Fría: «En la práctica, salvo algunas excepciones, la mayoría de los académicos y políticos rusos [de la época soviética] empleaban el paradigma realista - sin saberlo- por medio de su enfoque estatocéntrico en la búsqueda del poder e interés nacionales ${ }^{58}$.

33. Tras el surgimiento de la Federación Rusa como Estado independiente, la teoría se mantuvo inicialmente en un segundo plano; los estudios aplicados a formular una nueva política exterior se consideraban prioritarios en aquel momento. En cambio, tuvo lugar una rápida popularización de los temas de actualidad internacional en los think tanks y medios de comunicación; lo cual sirvió para llegar a un público más amplio, pero también —en opinión de algunos académicos- repercutió negativamente en la calidad de los debates ${ }^{59}$.

34. El estudio de la Teoría de las Relaciones Internacionales ha cobrado un nuevo impulso a partir de la década de los dos mil, con un cierto intercambio de papeles entre las dos «escuelas» surgidas en la Unión Soviética. Como hemos visto, los investigadores de IMEMO fueron los primeros en profundizar en cuestiones teóricas; los profesores de MGIMO, en cambio, se ocuparon más bien de desarrollar metodologías para el análisis aplicado. Sin embargo, en la etapa postsoviética IMEMO ha mantenido la orientación práctica propia de un think tank, mientras que las discusiones teóricas y epistemológicas se han desplazado a MGIMO y otras universidades, especialmente Moscú, San Petersburgo y Nizhni Novgorod ${ }^{60}$.

35. Desde entonces se ha configurado un debate en torno a dos paradigmas principales: el nacionalista o estatista —equiparable al realismo en la literatura científica occidental - y el liberal u occidentalista, con un claro predominio del primero en cuanto a número de seguidores. En los siguientes apartados examinaremos brevemente cada uno de ellos; sin entrar a analizar - por razones de espacio- otros posibles enfoques, como las teorías geopolíticas, el constructivismo social o el postestructuralismo ${ }^{61}$.

\footnotetext{
58 LebedeVA, M. M., op. cit., nota 8, p. 269.

59 Sergunin, A. A., "Discussions of International Relations in Post-Communist Russia», en TsYGANKov, A. P. y TsyganKov, P. A., op. cit., nota 11, p. 37.

60 Bogaturov, A. D., "Traditsia politicheskogo realizma v teorii mezhdunarodnyj otnosheni $\mathrm{v}$ Rossii» «La tradición del realismo político en la teoría de Relaciones Internacionales en Rusia»], en Kokoshin, A. A. y Bogaturov, A. D. (eds.), Mirovaia politika: teoria, metodologia, prikladnoi analiz, Moscú, Editorial URSS, 2004; JRustaliov, M., op. cit., nota 22; SERGUNIN, A., op. cit., nota 10, p. 78.

61 Las teorías geopolíticas alcanzaron gran difusión en Rusia durante los años noventa, sobre todo en sectores ultranacionalistas; no obstante, la calidad de sus publicaciones es muy desigual,
} 


\subsubsection{Realismo o nacional-estatismo}

36. La política exterior de Yeltsin siguió inicialmente una orientación liberal y de acercamiento a Occidente, tanto por las convicciones de los nuevos líderes como por sus intereses de política interna: la ayuda económica internacional y el apoyo político de Estados Unidos les eran imprescindibles para mantenerse en el poder. Sin embargo, el desencanto con la actitud de Washington y el auge del nacionalismo en la opinión pública pusieron fin a esa etapa en 1996, con el nombramiento de Yevgeni Primakov como ministro de Asuntos Exteriores. Primakov era un académico especialista en Oriente Medio, que en la época soviética había llegado a ser director de IMEMO (1985-1989) y del Instituto de Estudios Orientales (1977-1985); por tanto, su pensamiento debe entenderse en el contexto de la popularidad del realismo entre los investigadores de la Academia de Ciencias. Su etapa como ministro, y después primer ministro, en los gobiernos de Yeltsin, estuvo claramente basada en un enfoque teórico realista: el principal objetivo debía ser recuperar el estatus de Rusia como potencia (derzhava) dentro de un sistema internacional multipolar, en el que Estados Unidos ya no pudiera imponer su hegemonía ${ }^{62}$.

37. La defensa de ese estatus, denominada derzhavnichestvo - que suele traducirse como «nacionalismo» o "estatismo»— es hoy la principal escuela de pensamiento en el debate académico ruso; aunque se trata de una tradición heterogénea, en la que conviven distintas teorías y metodologías ${ }^{63}$. La primera en aparecer fue la del análisis histórico, continuadora de los primeros trabajos publicados en tiempos de la URSS. En segundo lugar, el análisis estructural o sistémico, que estudia el funcionamiento y tendencias del sistema internacional entendido de forma global. Por último, se ha producido una aproximación a otras disciplinas en áreas como la Psicología Política o la Economía Política Internacional. De acuerdo con la tipología utilizada en inglés, el neorrealismo o realismo estructural y el realismo neoclásico serían

\footnotetext{
incluyendo desde trabajos académicos a otros puramente ideológicos. Un ejemplo es el neoeurasianismo, basado en la oposición determinista - ya enunciada por la Geopolítica clásica - entre potencias marítimas y continentales, que presenta a Eurasia como una «civilización» cuya supervivencia se ve amenazada por Occidente. En cuanto al constructivismo o el postestructuralismo, son todavía minoritarios; de hecho, gran parte de los autores rusos identificados con estos enfoques trabajan en universidades extranjeras. Véase TsyganKov, A. P., Russkaia mezhdunarodnaia teoria: tri traditsii [La teoría internacional rusa: tres tradiciones], 2. ${ }^{\text {a }}$ ed., Moscú, Ru-Science, 2018; SERGUnin, A., op. cit., nota 10; Solovyev, E. G., "Geopolitics in Russia - Science or Vocation?», en Tsygankov, A. P. y TsyGANKov, P. A., op. cit., nota 11, pp. 127-142; LARUElLE, M., Russian Eurasianism: An Ideology of Empire, Washington/Baltimore, Woodrow Wilson Center Press/Johns Hopkins University Press, 2008; MaKarychev, A. y Morozov, V., «Is "Non-Western Theory" Possible? The Idea of Multipolarity and the Trap of Epistemological Relativism in Russian IR», International Studies Review, vol. 15, 2013, núm. 3, pp. 328-350.

62 PrImakov, Y. M., «Mezhdunarodnye otnoshenia v nakanune XXI veka: problemy, perspektivy» [«Las relaciones internacionales en el umbral del siglo XxI: problemas, perspectivas»], en SHAKLEINA, T. A., op. cit., nota 13, pp. 193-203.

${ }^{63}$ Shakleyina, T. A. y Bogaturov, A. D., op. cit., nota 23, pp. 62-66.
} 
hoy las teorías mayoritarias en Rusia; aunque también hay quienes reivindican el realismo clásico, como Timofei Bordachev ${ }^{64}$.

38. Sus líneas de investigación principales han sido la evolución del orden internacional de la postGuerra Fría y la estrategia de cada una de las grandes potencias. La mayoría de ellos mantiene una posición muy crítica hacia el intervencionismo de Estados Unidos: por ejemplo, Alexei Bogaturov considera que el unilateralismo estadounidense dificulta el surgimiento de una sociedad internacional —en el sentido de Hedley Bull- basada en normas compartidas. Esto habría dado lugar a un equilibrio inestable, en el que países como Rusia se han resistido a los intentos de «absorción» por parte de Occidente, tratando de sustituir la «unipolaridad pluralista» de la postGuerra Fría por una verdadera multipolaridad ${ }^{65}$. No obstante, Bogaturov se encuadra en una versión «ilustrada» del nacional-estatismo, que no concibe el resurgimiento ruso como una restauración imperial; por el contrario, el papel de actor global influyente solo podrá mantenerse si va acompañado de reformas internas y respeto a los derechos individuales ${ }^{66}$. En la misma línea, Tatiana Shakleina afirma que «el mundo no necesita un hegemón ni un líder», y propone un marco multilateral —más en forma de "concierto de potencias» que de instituciones- como el más adecuado para frenar tentaciones agresivas ${ }^{67}$.

39. Los principales desacuerdos se han producido en torno a cuál debería ser la respuesta de Rusia ante la preeminencia de Occidente. Para los más radicales, las ambiciones de Estados Unidos y el debilitamiento de la soberanía del Estado-nación — resultado, a su vez, del proceso globalizador impulsado por Washington - amenazan directamente la seguridad de Rusia, y justificarían adoptar una estrategia más intervencionista en el exterior. En cambio, los más pragmáticos consideran la globalización como un fenómeno inevitable, no controlado exclusivamente por Estados Unidos. La defensa de los intereses nacionales rusos sería compatible con mantener relaciones estables con Occidente, e incluso cooperar cuando sea beneficioso para ambas partes; pero sin ingenuas esperanzas de que las rivalidades vayan a desaparecer en el futuro ${ }^{68}$. Al mismo tiempo, Rusia debería aprovechar las ventajas

64 Bordachev, T., "Russia Needs a Realist Paradigm», Russian International Affairs Council, 11 de noviembre de 2014, disponible en http://russiancouncil.ru/en/analytics-and-comments/analytics/russianeeds-a-realist-paradigm/?sphrase_id=16480079.

65 Bogaturov, A. D., «Pliuralisticheskaia odnopoliarnost» [«Unipolaridad pluralista»], en BogAturov, A. D., Kosolapov, N. A. y Jrustaliov, M. A., Ocherki teorii i metodologii politicheskogo analiza mezhdunarodnyj otnosheni, Moscú, NOFMO, 2002, pp. 283-296; Bogaturov, A. D., "Globalizatsia kak "sindrom pogloschenia" v mezhdunarodnoi politike» [«La globalización como "síndrome de la absorción” en la política internacional»], pp. 335-355.

${ }^{66}$ Tsygankov, A. P. y Tsygankov, P. A., "Prosveschennoe derzhavnichestvo (A. D. Bogaturov i rossiiskaia teoria mezhdunarodnyj otnosheni)» [«Estatismo ilustrado (A. D. Bogaturov y la teoría rusa de las Relaciones Internacionales)»], Polis. Politicheskie issledovania, 2017, núm. 4, pp. 175-185.

67 Shakleina, T., «Liderstvo i sovremenny mirovoi poriadok» [«El liderazgo y el orden mundial contemporáneo»], en Mezhdunarodnye protsessy, vol. 13, 2015, núm. 4 (43), pp. 6-19, esp. p. 17.

68 Shakleyina, T. A. y Bogaturov, A. D., op. cit., nota 23, pp. 66-68; Bogaturov, A. D., op. cit., nota 60. La política exterior de Putin ha oscilado, de hecho, entre estas dos tendencias, alternando 
que le otorga su extensión en dos continentes para incrementar su influencia tanto en el espacio postsoviético como en Asia-Pacífico, mediante la presencia en foros multilaterales y la coordinación de los distintos instrumentos —diplomáticos, económicos y militares- de su política exterior ${ }^{69}$.

\subsubsection{Liberalismo u occidentalismo}

40. Los seguidores del paradigma liberal de las Relaciones Internacionales son menos numerosos en Rusia que los realistas o nacional-estatistas, pero aun así mantienen una importante presencia en el mundo académico. Comparten una posición en general occidentalista, favorable a la globalización y la pertenencia a instituciones internacionales. Dependiendo de los autores, podríamos equipararlos a distintas corrientes del mainstream anglosajón: bien al institucionalismo neoliberal — centrado en el funcionamiento interno de las organizaciones internacionales, y su papel en la creación y mantenimiento del orden global - o al internacionalismo liberal de los defensores de la "paz democrática» y el «intervencionismo humanitario». En el fondo, consideran que los principales problemas de Rusia son de carácter interno y que la política exterior debe estar al servicio de la modernización del país; por lo que suelen prestar menor atención a los factores militares y geopolíticos, no tan relevantes para ellos como los geoeconómicos ${ }^{70}$.

41. Para la mayoría de ellos, la democracia representa el único futuro aceptable para Rusia, que debería considerar a los países con esta forma de gobierno como sus modelos y aliados naturales; rechazando, en cambio, el acercamiento a China, que solo contribuye a mantenerla anclada en un modelo autoritario de desarrollo. Vladimir Kulagin, por ejemplo, ha sostenido una concepción cercana a la «paz democrática», argumentando que el progresivo avance de la democracia en el mundo es una tendencia imparable, que hace disminuir el número de conflictos interestatales. Esto dará lugar, en su opinión, a la emergencia de un nuevo sistema caracterizado por la «unipolaridad democrática»; en lugar de la multipolaridad que defienden los realistas, donde cada una de las potencias seguiría manteniendo su propio

etapas de mayor pragmatismo con otras de enfrentamiento. Sin embargo, en los últimos años ha incluido - al menos, en el plano discursivo - ciertos elementos culturales e identitarios, que la distancian de una definición puramente realista del interés nacional. Véase SAKWA, R., Russia Against the Rest: The Post-Cold War Crisis of World Order, Cambridge, Cambridge University Press, 2017, pp. 105-135.

69 Rogov, S. M., «Izoliatsia ot integratsii» [«Aislamiento de la integración»], en SHAKLEINA, T. A., op. cit., nota 13, pp. 269-280.

${ }_{70}$ Sergounin, A., «Russia: IR at a Crossroads», en Tickner, A. B. y Wæver, O. (eds.), International Relations Scholarship Around the World, Abingdon, Routledge, 2009, pp. 223-241, esp. p. 233; TsYgankov, P. A. y Tsygankov, A. P., «Dilemmas and Promises of Russian Liberalism», en Tsygankov, A. P. y Tsygankov, P. A., op. cit., nota 11, pp. 83-106; Tsygankov, A. P. y Tsygankov, P. A., «Russian Theory of International Relations», en Oxford Research Encyclopedia of International Studies, Oxford, Oxford University Press, 2010, disponible en http://internationalstudies.oxfordre.com/. 
sistema ${ }^{71}$. También han contribuido a este debate politólogos como Andrei Melville, que estudia la difusión transnacional de la democracia y el surgimiento de nuevos tipos de régimen con diferentes grados de autoritarismo, entre los que se incluye Rusia ${ }^{72}$.

42. Los liberales tampoco aceptan el equilibrio de poder como un mecanismo adecuado para garantizar la estabilidad, por tratarse de un modo de relación moralmente inaceptable, que debería ser sustituido por reglas e instituciones. Así, Yuri Davydov ha defendido un orden internacional basado en los valores democráticos, el «poder blando» y el avance de los procesos de interdependencia y globalización; aunque sin esperar por ello que la soberanía del Estado-nación o el carácter anárquico del sistema internacional vayan a desaparecer ${ }^{73}$.

43. El espacio postsoviético también ha sido uno de los principales temas para los investigadores. Muchos apoyan procesos como la Unión Económica Eurasiática, reflejo de la interdependencia entre los países vecinos, que proporciona a Rusia oportunidades para su desarrollo económico y exportaciones. Esta posición favorable a la integración regional es compartida por los realistas, aunque con argumentos diferentes: mantener la seguridad en su periferia e impedir la penetración de alianzas rivales, principalmente la $\mathrm{OTAN}^{74}$. En cambio, para occidentalistas como Dmitri Trenin, el liderazgo de Rusia en el espacio postsoviético está irremediablemente unido a su pasado imperial; el futuro debería pasar por renunciar a las ambiciones de mantener una zona de influencia en Eurasia, optando decididamente por la aproximación e integración con el resto de Europa ${ }^{75}$.

44. Gran parte de estos académicos estudian la participación de Rusia en negociaciones multilaterales y sus relaciones con organizaciones como la UE o la OSCE ${ }^{76}$. En este ámbito, existe una amplia variedad en cuanto al

${ }^{71}$ Kulagin, V. M., «Mir v XXI veke: mnogopoliusny balans sil ili globalny Pax democratica? Guipoteza "demokraticheskogo mira” v kontekste alternativ mirovogo razvitia» [ «El mundo en el siglo XXI: ¿equilibrio de poder multipolar o pax democratica global? La hipótesis de la "paz democrática" en el contexto de las alternativas de desarrollo mundial»], en Polis. Politicheskie issledovania, 2000, núm. 1, pp. 23-37; KuLAGIN, V. M., «Globalnaia ili mirovaia bezopasnost?» [«¿Seguridad global o mundial?»], en Mezhdunarodnye protsessy, vol. 5, 2007, núm. 2 (14), pp. 38-51.

72 Melville, A. Y., «Stanovlenie transnatsionalnoi politicheskoi sredi i "volny" demokratizatsii» [«La formación del entorno político transnacional y las "olas” de democratización»], en ToRKUNOv, A. V., op. cit., nota 16, pp. 77-100; MeLVILlE, A. Y., «Liberalnaia vneshnepoliticheskaia alternativa dlia Rossii?» [¿Una alternativa liberal de política exterior para Rusia?»], en SHAKLEINA, T. A., op. cit., nota 13 , pp. 330-339.

${ }^{73}$ Davydov, Y. P., Norma protiv sily. Problema miroregulirovania [La norma frente a la fuerza: el problema de la regulación del mundo], Moscú, Nauka, 2002; DAvydov, Y. P., "Poniatie "zhestkoi” i "miagkoi” sily v teorii mezhdunarodnyj otnosheni» [ "El concepto de poder "duro" y "blando" en la teoría de las Relaciones Internacionales»], Mezhdunarodnye protsessy, vol. 2, 2004, núm. 1 (4), pp. 69-80.

${ }^{74}$ Tsygankov, A. P., "Mastering Space in Eurasia: Russia's Geopolitical Thinking After the Soviet Break-Up», Communist and Post-Communist Studies, vol. 36, 2003, núm. 1, pp. 101-127.

75 Trenin, D., The End of Eurasia: Russia on the Border Between Geopolitics and Globalization, Washington, Carnegie Endowment for International Peace, 2001.

76 Lebedeva, M. M., «From Prominence to Decline: Russian Studies of International Negotiations», en Tsygankov, A. P. y Tsygankov, P. A., op. cit., nota 11, pp. 175-193; Zagorski, A. V., «Russia- 
empleo de argumentos normativos: mientras que algunos se limitan a analizar las instituciones y normas internacionales para explicar científicamente su evolución, otros enfatizan la importancia de estas para la construcción de un orden internacional más pacífico y justo. El enfoque liberal se centra hoy en destacar la interdependencia mutua entre Rusia y Occidente, así como las oportunidades para la cooperación, pero sin llegar a reivindicar el ingreso en las instituciones euroatlánticas ${ }^{77}$.

\section{ENTRE EL PARTICULARISMO Y LA OCCIDENTALIZACIÓN: LA ESCUELA RUSA DE RELACIONES INTERNACIONALES}

45. En los últimos años, distintos internacionalistas rusos -ante todo, los identificados con el realismo- han defendido la preservación de una Escuela Rusa que formule sus propias teorías, para superar lo que consideran un excesivo seguidismo de los enfoques estadounidenses. El punto de partida fue un artículo de Alexei Bogaturov del año 2000, en el que reflexionaba sobre la evolución de la disciplina en la década anterior, a partir de su experiencia organizando cursos para jóvenes investigadores ${ }^{78}$. Pese a que la mayoría de ellos conociera y citara las teorías anglosajonas, su aplicación empírica a la política exterior de Rusia no se ajustaba —-según el autor - a las características peculiares del país; cuya experiencia histórica no coincide con la de otros Estados, incluso aquellos que también han sufrido regímenes totalitarios. Bogaturov concluía que el "paradigma de la asimilación» del pensamiento occidental adoptado por las nuevas generaciones era simplista e inadecuado, y corría el riesgo de convertir a los académicos rusos en meros traductores de la literatura científica extranjera.

46. Entre los seguidores del enfoque liberal, Marina Lebedeva no comparte esas críticas al sesgo estadounidense de la disciplina; no solo las formuladas en Rusia, sino también las de autores como Amitav Acharya, Barry Buzan $^{79}$ o Robert $\mathrm{Cox}^{80}$, cuya advertencia de que la teoría «siempre es para alguien y para un propósito determinado» considera exagerada. El «americanocentrismo» o "eurocentrismo» predominantes serían un resultado objetivo del estadio más avanzado en el que se encuentra esta ciencia en los países occidentales; en comparación con su relativa novedad en Rusia, donde los debates sobre cuestiones teóricas y su expansión a universidades fuera de

\footnotetext{
EU Relations at a Crossroads: Common and Divergent Interests», RIAC Working Paper, núm. 31, 2016, disponible en http://russiancouncil.ru/upload/Russia-EU-Crossroads-Paper31-en.pdf.

77 Lebedeva, M. M. y Kharkevich, M. V., «Teoria mezhdunarodnyj otnosheni v zerkale sovremennyj rossiiskij issledovani» [La teoría de las Relaciones Internacionales a la luz de los estudios rusos contemporáneos»], en Vestnik MGIMO-Universiteta, 2016, núm. 5, pp. 7-19.

78 Bogaturov, A. D., «Desiat let paradigmy osvoienia» [«Diez años del paradigma de la asimilación»], en Pro et Contra, vol. 5, 2000, núm. 1, disponible en http://obraforum.ru/bogaturov6.htm.

${ }^{79}$ Acharya, A. y Buzan, B., "Conclusion: On the Possibility of a Non-Western International Relations Theory», en Acharya, A. y BuZAN, B., op. cit., nota 3, pp. 221-237.

${ }^{80}$ Cox, R. W., "Social Forces, States and World Orders: Beyond International Relations Theory», Millennium: Journal of International Studies, vol. 10, 1981, núm. 2, pp. 126-155, esp. p. 128.
} 
Moscú solo comenzaron realmente a partir de 1991. No obstante, para Lebedeva sí es posible y deseable realizar aportaciones propias: por ejemplo, mediante una síntesis entre las tradiciones científicas extranjeras y las autóctonas, o elaborando de forma crítica posibles alternativas a los enfoques occidentales. En todo caso, debe evitarse caer en actitudes nacionalistas que lleven de nuevo al aislamiento a los académicos rusos; los cuales, de hecho, ya están apreciando cierto enfriamiento de los contactos con sus colegas de otros países, como resultado de la conflictividad en las relaciones políticas a partir de la crisis de Ucrania ${ }^{81}$.

47. Los académicos rusos que trabajan en el extranjero también han opinado sobre esta polémica. Una contribución especialmente dura ha sido la de Andrey Makarychev y Viatcheslav Morozov, actualmente profesores de la Universidad de Tartu (Estonia) e identificados con el reflectivismo. Ambos han acusado a los realistas de su país de "relativismo epistemológico», por defender la pluralidad de escuelas nacionales como algo inherentemente positivo, sin examinar su contribución. Además, han alertado de lo que consideran una excesiva cercanía entre el realismo mayoritario y la política exterior del Kremlin, en temas como la defensa de la multipolaridad o la oposición a la hegemonía de Estados Unidos. Esta supuesta ideologización haría que los internacionalistas rusos prefieran mantenerse anclados en debates internos, evitando someterse a la valoración de especialistas extranjeros ${ }^{82}$.

48. Otros como Andrei Tsygankov, profesor de la Universidad Estatal de San Francisco (Estados Unidos), muestran una actitud mucho más integradora hacia sus colegas que permanecen en Rusia. Aunque él mismo adopta una perspectiva constructivista - crítica, por tanto, con el realismo-, también ha trabajado para difundir entre el público global las diversas corrientes del pensamiento internacional de su país. Varias de estas publicaciones han sido escritas con su padre, Pavel Tsygankov, profesor de la Universidad Estatal de Moscú y autor del manual más importante en ruso sobre Teoría de las Relaciones Internacionales, que ha tenido un papel fundamental en la introducción de los «grandes debates» del mainstream en la enseñanza ${ }^{83}$.

81 Lebedeva, M. M., «Rossiskie mezhdunarodnye issledovania...», op. cit., nota 53, pp. 85-87; LEBedeva, M. M., Russian Studies of International Relations: From the Soviet Past to the Post-Cold War Present, Stuttgart, Ibidem-Verlag, 2018, p. 163.

82 Makarychev, A. y Morozov, V., op. cit., nota 61, pp. 329-330. No deja de ser paradójico que esta crítica proceda de una perspectiva reflectivista, que debería problematizar la «objetividad» de las teorías occidentales frente a la "subjetividad» de las rusas; ambas han sido construidas discursivamente en un contexto cultural determinado, a partir de unos presupuestos normativos condicionados por los valores y la experiencia histórica de sus países.

83 Así lo considera Lebedeva, M. M., op. cit., nota 17, p. 70. En la edición de 2003, el libro se centraba en el debate interparadigmático entre neorrealismo, neoliberalismo y neomarxismo, añadiendo después un apartado sobre las teorías más sociológicas: la Escuela Francesa de Bertrand Badie, Didier Bigo o Marie-Claude Smouts; la Escuela Inglesa de Hedley Bull, Martin Wight o Barry Buzan; y la Escuela Americana —en la que Tsygankov incluye el constructivismo social— de Alexander Wendt, Martha Finnemore o Peter Katzenstein. La edición de 2018 se estructura en torno a los cuatro great debates, profundizando sobre todo en el más reciente, entre racionalismo y reflectivismo. TsYGANKOV, P. A., Teoria mezhdunarodnyj otnosheni [Teoría de las Relaciones Internacionales], Moscú, Gardariki, 2003, 
49. De acuerdo con estos últimos autores, el desarrollo de las Relaciones Internacionales en Rusia puede resumirse en dos tendencias contradictorias $^{84}$. Por un lado, la disciplina se ha hecho más plural gracias a la incorporación de nuevas teorías, que han acabado con el monopolio del paradigma dominante en cada momento: así, el marxismo-leninismo fue sustituido por el realismo, y después el liberalismo ha cuestionado la primacía de los realistas. Por otro lado, aunque esta diversidad haya tenido un efecto positivo, en algunos casos ha llevado a una excesiva occidentalización, que no implicaría tanto un aprendizaje como la asimilación acrítica de las teorías estadounidenses, considerándolas como las únicas científicas. La percepción de los enfoques rusos y extranjeros como opciones incompatibles parte de la propia división entre asignaturas: las tradiciones intelectuales autóctonas se estudian en Historia del Pensamiento Político, mientras que la Teoría de las Relaciones Internacionales está centrada en los paradigmas anglosajones ${ }^{85}$.

50. El riesgo de depender en exceso de los enfoques extranjeros también se ve agravado - en opinión de Pavel Tsygankov- por el sistema de evaluación del profesorado universitario, que les obliga cada vez más a publicar en inglés ${ }^{86}$. Algunos académicos rusos han llegado a denunciar un filtro ideológico en las revistas anglosajonas, de las cuales se excluiría a todos aquellos que no compartan «axiomas estadounidenses» como la defensa de la globalización o la expansión de la democracia ${ }^{87}$. Estos recelos excesivos contribuyen, lamentablemente, a fortalecer el «americanocentrismo» de la disciplina y el desconocimiento de los autores rusos fuera de su país, al disuadirles de participar en los debates en inglés.

51. En el otro extremo se encuentran quienes tratan de aproximarse cada vez más al mainstream occidental. Un ejemplo es la Facultad de Relaciones Internacionales de la Universidad Estatal de San Petersburgo, que asume una concepción docente en la que los debates se agrupan en paradigmas de alcance universal, con idénticos referentes que el mundo anglosajón ${ }^{88}$. Esta perspectiva está, lógicamente, más extendida entre profesores que imparten grados o másteres en Relaciones Internacionales en inglés, como los que se han creado en San Petersburgo, MGIMO o la Escuela Superior de Econo-

pp. 155-163; Tsygankov, P. A. (ed.), Teoria mezhdunarodnyj otnosheni. Uchebnik dlia akademicheskogo bakalavriata [Teoría de las Relaciones Internacionales. Manual para estudios de grado], Moscú, Yurait, 2018, pp. 43-48.

${ }^{84}$ Tsygankov, A. P. y Tsygankov, P. A., op. cit., nota 11, pp. 20-26.

85 Tsygankov, A. P., «Rossiiskaia teoria mezhdunarodnyj otnosheni: kakoi yei byt?» [«a teoría rusa de las Relaciones Internacionales: ¿cuál debería ser?»], en Sravnitelnaia politika, vol. 5, 2014, núm. 2 (15-16), pp. 65-83, esp. p. 66.

86 BARnashov, O. V., op. cit., nota 49, p. 190.

87 Fenenko, A., «Pochemu v Amerike ne liubiat publikovat rossiiskij avtorov?» [«Por qué en Estados Unidos no les gusta publicar a los autores rusos?»], en Mezhdunarodnye protsessy, vol. 14, 2016, núm. 1 (44), pp. 172-180. Por supuesto, esa dificultad se debe también a diferencias de tipo metodológico: la tendencia cuantitativista de las Relaciones Internacionales estadounidenses, por influencia de la Ciencia Política, frente al análisis histórico-descriptivo de muchos trabajos rusos.

${ }^{88}$ Zaslavskaya, N., op. cit., nota 38, p. 10; TsvetKova, N. (ed.), Russia and the World: Understanding International Relations, Lanham, Lexington Books, 2017. 
mía. La creciente participación de académicos rusos en los congresos de la International Studies Association (ISA) y la European International Studies Association (EISA) es otra muestra de esta apertura.

\section{CONCLUSIONES}

52. A partir de la disolución de la URSS, las Relaciones Internacionales rusas han conseguido superar las barreras doctrinales que frenaban su desarrollo; si bien siguen existiendo inercias del pasado, como el predominio del paradigma realista. Sus principales fortalezas son su reconocimiento como ciencia autónoma y como titulación universitaria, cuya difusión desde Moscú a otras regiones ha creado una «masa crítica» de internacionalistas con enorme potencial. El debate académico se ve reflejado en multitud de libros y revistas científicas, donde los autores extranjeros son citados con total normalidad.

53. No obstante, en otros aspectos queda mucho camino por recorrer. La mayoría de los académicos siguen limitándose al análisis aplicado de la política internacional, asumiendo enfoques tradicionales como el neorrealismo o el institucionalismo neoliberal; en cambio, las discusiones teóricas y epistemológicas — como el actual «cuarto debate»— se limitan a un grupo comparativamente reducido. Esto da lugar a que el constructivismo social o el postestructuralismo aún no hayan arraigado en Rusia: salvo contadas excepciones, las referencias a ellos suelen ser resúmenes o comentarios de los debates occidentales, más que aplicaciones propias.

54. El principal problema que afrontan hoy las Relaciones Internacionales rusas es el desconocimiento global de su producción investigadora, que ya no se explica del todo por una cuestión lingüística. Cada vez más autores rusos publican en inglés, pero solo los que trabajan en universidades anglosajonas obtienen un impacto comparable al de sus colegas estadounidenses o británicos. Parte del motivo reside en la percepción orientalista —heredada de la «kremlinología» de la Guerra Fría- de Rusia como mero objeto de estudio para otros países; no como un sujeto activo capaz de investigar, a su vez, sobre diferentes partes del mundo, incluyendo su propia política exterior. Esta actitud se manifiesta en una escucha selectiva, en la que aquellas voces que coinciden con las preconcepciones sobre Rusia asumidas en Occidente - es decir, los liberales más atlantistas y los nacionalistas más agresivos - son tomadas como representantes de toda la sociedad rusa, mientras que la gran mayoría de sus expertos y académicos son raramente citados.

55. La posibilidad y conveniencia de una teoría internacional «postoccidental» tiene características peculiares en el caso ruso, donde el rechazo a la hegemonía de los autores anglosajones ha partido del nacional-estatismo o derzhavnichestvo; una corriente influida — paradójicamente- desde la Guerra Fría por el realismo estadounidense, con el que comparte una misma con- 
cepción estatocéntrica y basada en el equilibrio de poder. Por tanto, más que una diferencia teórica insalvable entre los enfoques «nacionales» y «extranjeros», lo que subyace a la controversia sobre la necesidad de una Escuela Rusa es el debate político entre nacionalismo y occidentalismo, que no puede entenderse al margen de sus implicaciones psicológicas: muy especialmente, la memoria de la durísima transición económica de los años noventa, en la que las recetas neoliberales importadas desde Occidente tuvieron gran parte de responsabilidad.

56. El gran desafío para el futuro es continuar la pluralización de enfoques ya iniciada en 1991, reinterpretando los paradigmas extranjeros a la luz de sus propias corrientes intelectuales, y elaborando nuevas teorías que puedan ser difundidas fuera de Rusia. Los temores a que la occidentalización del mundo académico anulase el pensamiento autóctono tuvieron su fundamento en una etapa concreta de crisis, en la que los investigadores rusos debían adaptar sus proyectos a las expectativas de las entidades extranjeras que los financiaban. Sin embargo, el riesgo más probable hoy — con una ciencia de las Relaciones Internacionales plenamente consolidada en ese país- es precisamente el opuesto: alejarse de los grandes debates sobre problemas universales, por influencia del clima de confrontación y desconfianza en la política exterior.

57. Hasta ahora, los internacionalistas rusos han sabido combinar el mantenimiento de una identidad propia con la apertura a nuevas ideas y una presencia global cada vez mayor. Solo evitando tentaciones aislacionistas podrán llegar a obtener un reconocimiento acorde con su trabajo, abandonando la posición subalterna a la que se ven relegados por el etnocentrismo del mainstream de la disciplina.

\section{RESUMEN}

\section{LAS RELACIONES INTERNACIONALES EN RUSIA: DESARROLLO, ENFOQUES Y DEBATES}

Este artículo tiene como objetivo analizar el surgimiento y desarrollo de las Relaciones Internacionales como disciplina científica en Rusia, incluyendo sus debates más recientes. En la introducción, se contextualiza el objeto de estudio dentro de la creciente atención hacia los debates académicos en lenguas distintas del inglés, como respuesta a la hegemonía de los autores y paradigmas estadounidenses. El siguiente apartado describe los comienzos de la investigación científica y enseñanza universitaria de las Relaciones Internacionales en la URSS, así como los cambios ocurridos en la Federación Rusa independiente. El tercer apartado compara sus diversas concepciones de la disciplina, posición dentro de las ciencias sociales y principales enfoques teóricos en la actualidad. El cuarto apartado profundiza en el debate sobre la conveniencia de mantener una escuela autóctona de Relaciones Internacionales, frente a quienes prefieren asimilar en mayor medida los conceptos y paradigmas anglosajones. Por último, en las conclusiones se reflexiona sobre los obstáculos que afrontan los internacionalistas rusos para lograr un mayor reconocimiento global.

Palabras clave: Rusia, URSS, Relaciones Internacionales, ciencia, teoría, etnocentrismo. 


\section{ABSTRACT \\ INTERNATIONAL RELATIONS IN RUSSIA: DEVELOPMENT, APPROACHES, AND DEBATES}

This article aims to analyze the emergence and development of International Relations as a scientific discipline in Russia, including its most recent debates. In the introduction, we explain the object of study in the context of the growing attention towards academic debates in languages other than English, as a response to the hegemony of American authors and paradigms. The following section describes the beginnings of scientific research and university teaching of International Relations in the USSR, as well as the changes that have taken place in the independent Russian Federation. The third section compares their various conceptions of the discipline, position within the social sciences and main theoretical approaches in the present day. The fourth section examines the debate about the convenience of preserving a national school of International Relations, opposed by those who prefer to adopt Western concepts and paradigms. Finally, the conclusions reflect on the challenges faced by Russian International Relations scholars to achieve greater international recognition.

Keywords: Russia, USSR, International Relations, science, theory, ethnocentrism. 